\title{
Development of a Robust Library Management System
}

\author{
Ayodeji Iwayemi \\ Department of Computer Engineering \\ The Federal Polytechnic, Ile-Oluji, Nigeria
}

\author{
Sulaimon Oyeniyi Adebayo \\ Department of Computer Engineering \\ The Federal Polytechnic, Ile-Oluji, Nigeria
}

\begin{abstract}
The process of handling library activities manually is accompanied with time wastage and unnecessary stress. With regard to the aforementioned, the computerized system of handling library activities makes most effective use of existing library manpower and resources for the benefit of users. This design is aimed at providing solutions to various challenges faced by manual library system. It will not eliminate the existing manual system but will work side by side with the existing system. This system was developed using waterfall model. PHP, HTML, and CSS were used for designing of the frontend and MySQL as backend database technology. This robust design encompasses Library Management System and Online Library System. It is a website that allows students and staff to access the library easily and at the same time automate library processes by keeping record of library resources and allocating them automatically.
\end{abstract}

\section{General Terms}

Library Management System

\section{Keywords}

Library Management System, Integrated Library, Library Automation, Database, Waterfall Model, HTML, PHP, CSS, MySQL.

\section{INTRODUCTION}

The word library originated from the Latin name, liber, which means book. The library precedes books as the collection of clay tablets, papyrus and scrolls were housed or kept in the library before the emergence of books. A library can be defined as a place where the collection of records of human culture in diverse formats and languages are kept preserved, organized, interpreted and disseminated to meet the broad and varying information needs of individuals for knowledge recreation and aesthetic enjoyment.

Library is a fast-growing organism. A research conducted in 2010 explained that the ancient methods of maintaining library are no longer dynamic and efficient. Speedy retrieval and dissemination of information, better service for library users and application of modern technologies in the library system have become necessity in the 21 st century library operations [1]. Another research added that libraries exist to disseminate current literacy and artistic thought as well as scientific and technical innovation responsibilities which cover media such as films, videos, cassettes and tapes [2].

Integrated library system, also known as a library management system is an enterprise resource planning system that a library uses to track items owned, orders made, bills paid, and users who have borrowed from the library [3]. A library is a room, building or an institution where a collection of books and other research materials are kept [4].

$<$ Libraries can be categorized based on the functions they perform such as Academic Libraries, Public Libraries, School
Libraries, Special Libraries, National Libraries, Private Libraries and Electronic Libraries. Also, libraries consist of different sections such as: Administrative Section, Readers Service Section, Technical Services Section and Electronic Library Section. The absence of one will affect the output of others.

Library comprises one or more of the following sections base on the functions they are performing; Acquisition section, Technical section, Circulation section, Cataloguing section, Periodical section, Reference section, Reprographic section, Information Technology Section, Stack section, and Thesis/Dissertation Section.

Manual Library System involves lots of paper works as the library information including user data, staff data, book records, purchase records among others are all documented manually. Also, charging and discharging of books are done manually leading to waste of time and resources from the users and the library authority.

An investigation was carried out on the computer skills among librarians of academic libraries in Ondo and Ekiti States of Nigeria. It was established that there were shortages of computers and computer skills among professionals. The study recommended that more funds should be allotted for procurement of ICT infrastructure [5].

A research on computer literacy skills of professionals in Nigerian University libraries was conducted in 2006 where it was also established that most of the professionals do not possess high level of computer skills. The Study recommended that library managers and leaders should organize and offer in-house computer training programmes for librarians and enough computers should be provided [6]. Library Management System aids management of library resources in an effective and reliable way. A Standard Library Management System should include all the modules that are incorporated in the manual library system. An average Library Management System should be cost effective, should not interfere with the manual library system and should provide desired and justified result. The modules should depend on the purpose the library is to serve, and it should include, though not limited to the following features; Acquisition, Circulation, Serial Management, Barcode, Feedback, Flexibility, Multi User Environment, Search Engine, Database and Security.

\section{PROBLEMS OF MANUAL LIBRARY SYSTEM}

Having observed the existing manual system thoroughly, the existing manual library is still facing handful of challenges which indicate that it is time to migrate to library automation. Some of the challenges include:

- Time Wasting: There are lots of processes required in the manual library which leads to time wastage, especially in terms of charging and discharging of books.

- Loss of Data: The manual system involves documentation of records manually, lots of paper works 
were require for keeping user details as well as library resources. This data lost were cause mainly as a result of manual processing.

- Loss of Library materials: Since charging and discharging of books and other library materials are done manually, if record of the library material borrowed is lost, the material itself will be very difficult, if not impossible to retrieve back.

- Inadequacy of personnel: In an academia, libraries are expected to welcome new users at every session, which means library users are increasing from time to time. Unfortunately, library staff are not increasing thereby leaving the librarians with the challenge of having more work with lesser hands.

\section{SUMMARY OF PREVIOUS WORKS ON LIBRARY MANAGEMENT SYSTEM}

The first Library Management System to be review in this research is KOHA Library Management System. KOHA is not an acronym or abbreviation but a Maori word which means special kind of gift with expectation. KOHA as described by the KOHA website is the oldest Library Management System in existence that was first developed in 1999 , since then the system has been subjected to several modifications from then till date. Since the original implementation in 1999, KOHA functionality has been adopted by thousands of libraries worldwide, each adding features and functions, deepening the capability of the system. LibLime KOHA is the most functionally advanced open source ILS on the market today. The major k-leg of this system is that it is fully web-base, and it is not backed up with physical materials and hackers can easily tamper with information of users. Also, this system is an open source, and anybody is free to make contribution either relevant or not.

After the implementation of KOHA, hundreds of Library Management System has been developed but each with one setback or the other, the most setback is that most of them are computer software which can only be implemented on computer system alone for example, Library Management System developed by a final year student of the department of Computer Science, the Federal University, Oye-Ekiti, Ekiti State [7]

Also, a Library Management System was developed for School of Chemistry Bharathidasan University, India titled "Implementation of Automated Library Management System in the School of Chemistry Bharathidasan University using KOHA Open Source Software", the design has all Chemistry library collections collated in a single database, and it gives full control of the library collections and operations. However, the research lacks Infrastructure facility, environmental support and financial Resources and above all, open source (KOHA) was included in the design which give everyone access to be make contributions, either related or not [1].

A Library Management System was developed in 2014 that is aim at reducing cost and time. The system has many features which are not available in most Library Management System, such as option of online notice board about the workshop where Librarian will be able to provide a detailed description of workshops going in the college as well as nearby colleges, teacher login page where teacher can add any events being organized in the college and important suggestions regarding books, among other features [8].
Also, a Library Management System titled "An android cloud-based library management and authentication system" was developed in 2014. The design is user friendly, but as the name implies, it is platform dependent just as the name implies, it can only work on mobile phones [9]

Another Library Management System titled "A Web-based ELibrary System for Tertiary Institutions" which has multimedia facilities as part of it features was developed in 2017. However, the system is not cost effective [10].

Another library management system titled "Development of cloud computing in integrated library management and retrieval system" was developed in 2013. The designed system is reliable and security conscious, but it is costly to manage because of the facilities required for setting up a cloud database [11]

Also, another automatic library management system was designed in 2016, the design was titled "Automated Library Management System". The design aids fast processing of books and other library transactions but it is not cost effective [12].

An open source Library Management System software which is cost effective was developed in 2011. The K-leg of the design is that it uses Open source alone in which everybody is free to make contributions either relevant or not. Also, the design is platform dependent, it can only work of personal computers [13].

\section{MATERIALS AND METHODS}

In developing a Library Management System, certain modules of the system should be critically taken into consideration as these modules forms the fundamental part of the system. Without these modules, the system is as good as not be in existence. These modules include the Admin login, Student login, Staff login, Search book and Public access. Admin login enables the admin (in some places, the librarian or library staff) to monitor the whole system. The Student and Staff login, which can be used interchangeably as the user's login enables students and staff to have access to the resources of the system. Admin, student and staff login requires some authentication before having access to the system. However, there should be other parts of the system that will enable member of the public who were not authorized to access some of the resources of the system. When considering development of Library Management System from another perspective, it can as well be categorize into two (2) major parts i.e. the frontend and the backend. The frontend is the interface in which all the users of the system can login and access the system while the backend of the system is the database in which all the books and othermaterials of the system including user's login username and password are stored.

The frontend of this design was developed using html, php, and css, while the backend was developed with MySQL.

Summarily, HTML was used to write the whole codes for the development of the web pages, PHP for server-side scripting and CSS for the web pages styling. External styling was used. Also, MySQL was employed as the database technology. Figure 1 shows the data flow diagram for the homepage of this design. 


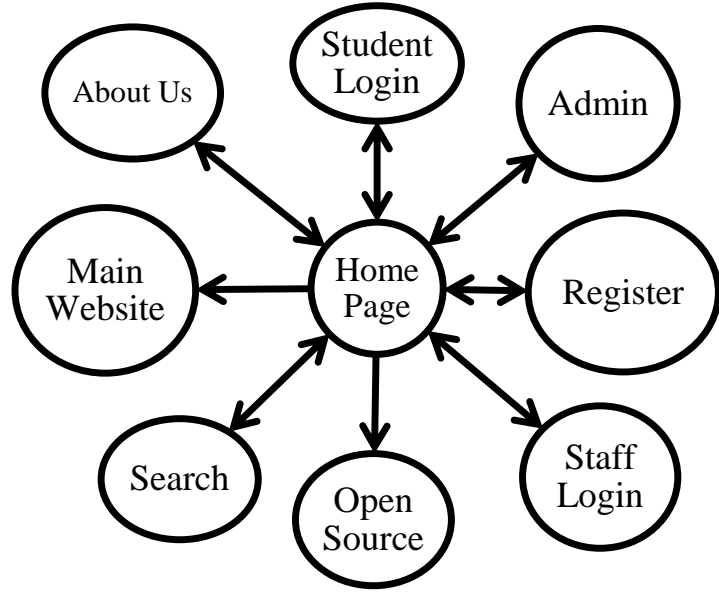

Figure 1: Home page data flow diagram

\subsection{System Flow Chart}

The system design flowchart, starting from the registration page, to the students' login page, to the staff login is presented in figure 2 .

\subsection{Software Engineering Model}

The software engineering model employed for this design was waterfall model. Waterfall model is often referred to as linearsequential life cycle model because it is used to create a system with linear and sequential approach. The model develops systematically from one phase to another in a downward fashion, just like water fall as the name implies. Each phase must be

completed before the next phase can begin and there must not be overlapping of phases. Output of a phase will be input of the next phase. The model is simple and easy to understand, and it is very easy to use. Also, it is easy to manage as each phase has specific outputs and review process.

A research argues that validation of the system against customer's requirements is left to the end of the process, at which time any change to the system's design or any implementation made at this stage will very costly [14].

The followings are the principal stages of waterfall model:

- Requirement gathering and analysis: This stage involves gathering of all the necessary requirements for the system to be developed. Most of the time, it requires consultation with system users. The information gathered is then redefined in a form understandable by the developer and the users. In this design, questionnaire was employed to gather information about the need for computer aided library as well as the features desired by the users and the librarians. Also, requirements of the design, both software and hardware that will carry out the workperfectly were also determined at this stage.

- System and Software Design: The System is designed based on the gathered information. The System design process helps in specifying hardware and software requirements of the design. It establishes overall system architecture. The designing of the system starts with frontend design and backend was later developed to serve as backbone for frontend.

- Implementation and unit testing: With input from system and software design stage, the system is first developed in small programs called unit. During this stage, software design is realized as a set of program units. Unit testing involves testing of each developed unit. The systems are in different modules, such as home page module, registration module, search book module, student log in module, staff log in module among others. Each module is developed separately and was tested to ensure they are producing desired output.

- Integration and System Testing: All the units that was tested from the implementation phase are integrated in to a single system. The units will then be tested as a complete system. The tested system can then be delivered to the users. All the modules were incorporated together to form a single, more robust system, which can also be referred to as the whole system. After successful integration of all the modules, the system was tested as a complete system, and the system as a whole meets the aim and objectives of this design.

- Operation and maintenance: Operation and maintenance is the usage of the system by the user. Normally, this is the longest phase of the model. Maintenance involves providing solutions to problems that were discovered during the development of the system and new errors that may occur as a result of the operation of the system. Operation and maintenance involve addition of new books and users, removing of users that are no more student/staff of the Polytechnic, removing of books and other materials that are no more in the Polytechnic library among other services.

Figure 3 shows the waterfall model block diagram. 


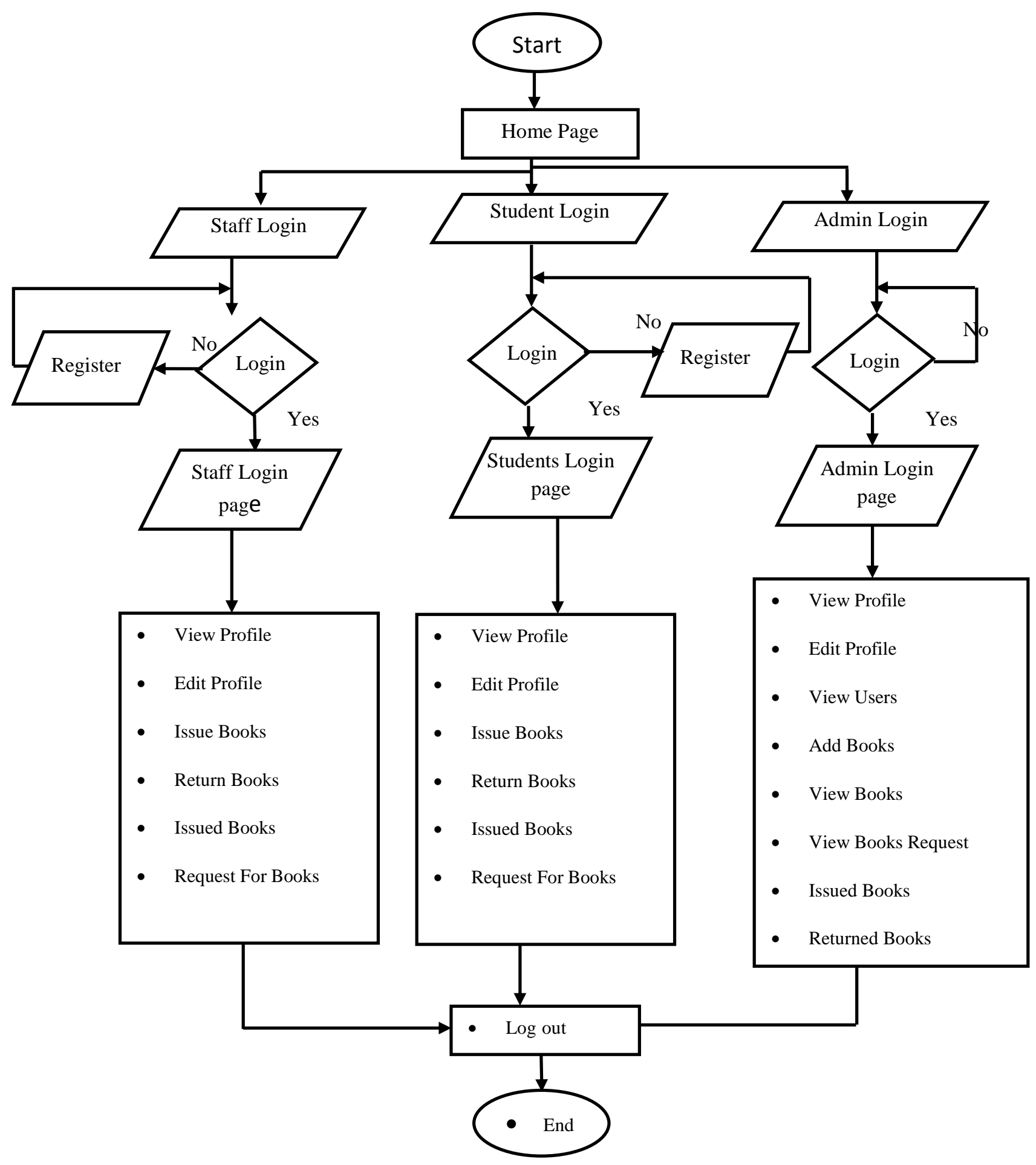

Figure 2: Flow Chart of the Design 


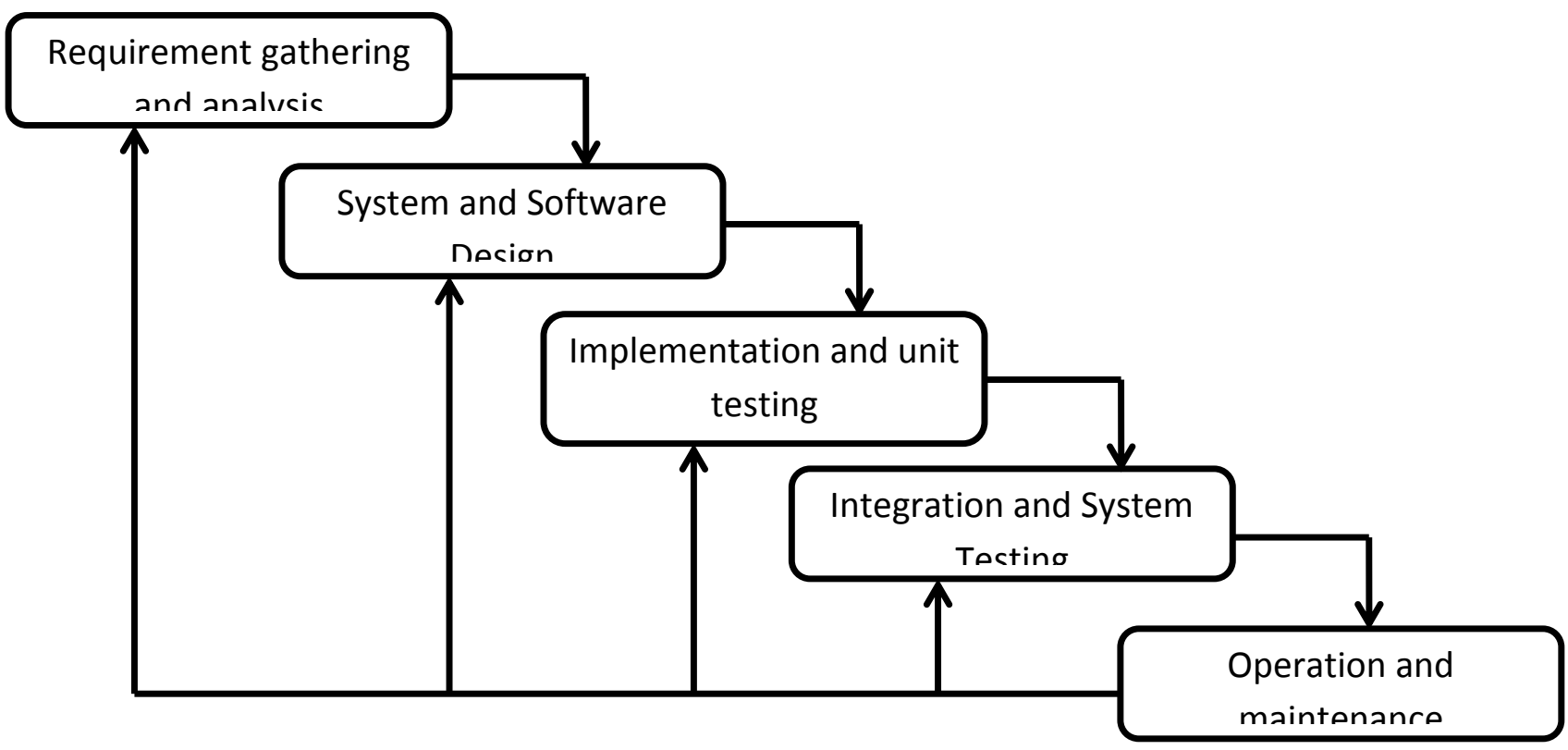

Figure 3: Waterfall model block diagram ([15]; [16]; [17])

\section{DESIGN REQUIREMENTS}

Design requirements include both the software and hardware requirements used for the designed system.

\subsection{Software Requirements}

- Operating System: The Operating System used was windows 8 as it is stable and user friendly. Avast antivirus was also used to ensure safety of the design especially at the developmental stages. The least recommended operating system is windows XP.

- Database: MySQL was used as database since it is simple to operate as it can retrieve records by simple queries in English Language.

- Developmental tools and programming languages: HTML was used to write the whole codes for the development of the web pages, PHP for server side scripting and CSS for the web pages styling. External styling was used.

\subsection{Hardware Requirements}

Processor: Intel core i5 2nd generation was used as processor because it can handle multitasking of computer systems i.e. it gives room for processing of multiple task at a time. However, the minimum recommended processor is Pentium 4.

RAM: 4GB RAM was used as it support faster processing of the design. However, this design can be carried out successfully on 1GB RAM.

Hard Disk: 500 GB Hard disk was used for this design. Any Hard Disk below 50 GB is not recommended for this design.

\section{RESULTS AND DISCUSSION}

The results achieved for this research were in two forms, the frontend results and the backend results. The newly developed system was tested on different platforms and certain amendments were made to ensure the system is performing the desired result. Each module was tested separately, and they were all performing desired output. The frontend results include the home page, registration page, student's login page, staff login page, add books page, borrow books page among others, while the backend results include users table, borrow details table, book table among others.

\subsection{Frontend Results}

Frontend result includes several web pages of the design such as home page, registration page, student log in page, staff log in page, search book page among others.

Home Page: Home page is the first interface of the designed system. It provides the basic page where student, staff and admin can click on to access the library system. The Register, Search, Open source, About Us and other sections are in this page. Figure 4 gives the details of the home page.

Registration Page: Every user is expected to register before having access to the full resources of the system. The user will provide the First name, Other names, Username, Password, Position, Mobile phone number, E-mail address, Matriculation Number, Passport Photograph, Department and level for registration. However, an automatic ID number is assigned to every user at the point of registration. Figure 5 gives the pictorial representation of the registration page.

Student Login Page: Student can log in with his username and password after he must have successfully registered on the Registration page. Students can also click on the "Forget Password" option to retrieve his password if forgotten.

Add Books Page: Only the admin has the authorized access to add a particular book to the library system. The library admin can add new books to the library as much as possible for the user to borrow and use. Figure 6 gives the pictorial representation of the Add Book Page.

Search Books Page: In manual Library system, cataloguing is used to search book out. This system has a module where users can search for any book that is in the library. The module is linked directly from the Home page interface of the system. Users are allowed to search for any book using one of the details of the book. 


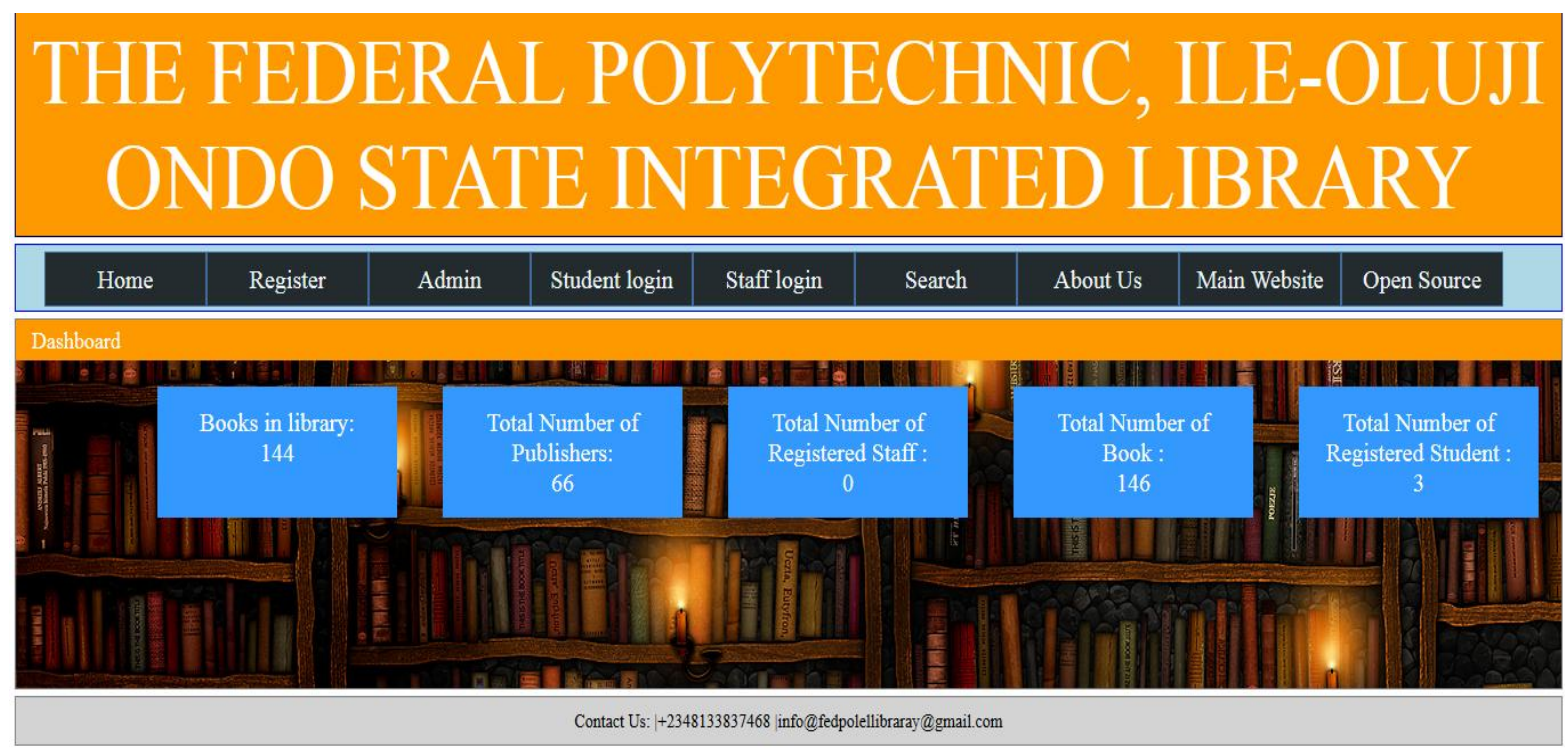

Figure 4: Home Page

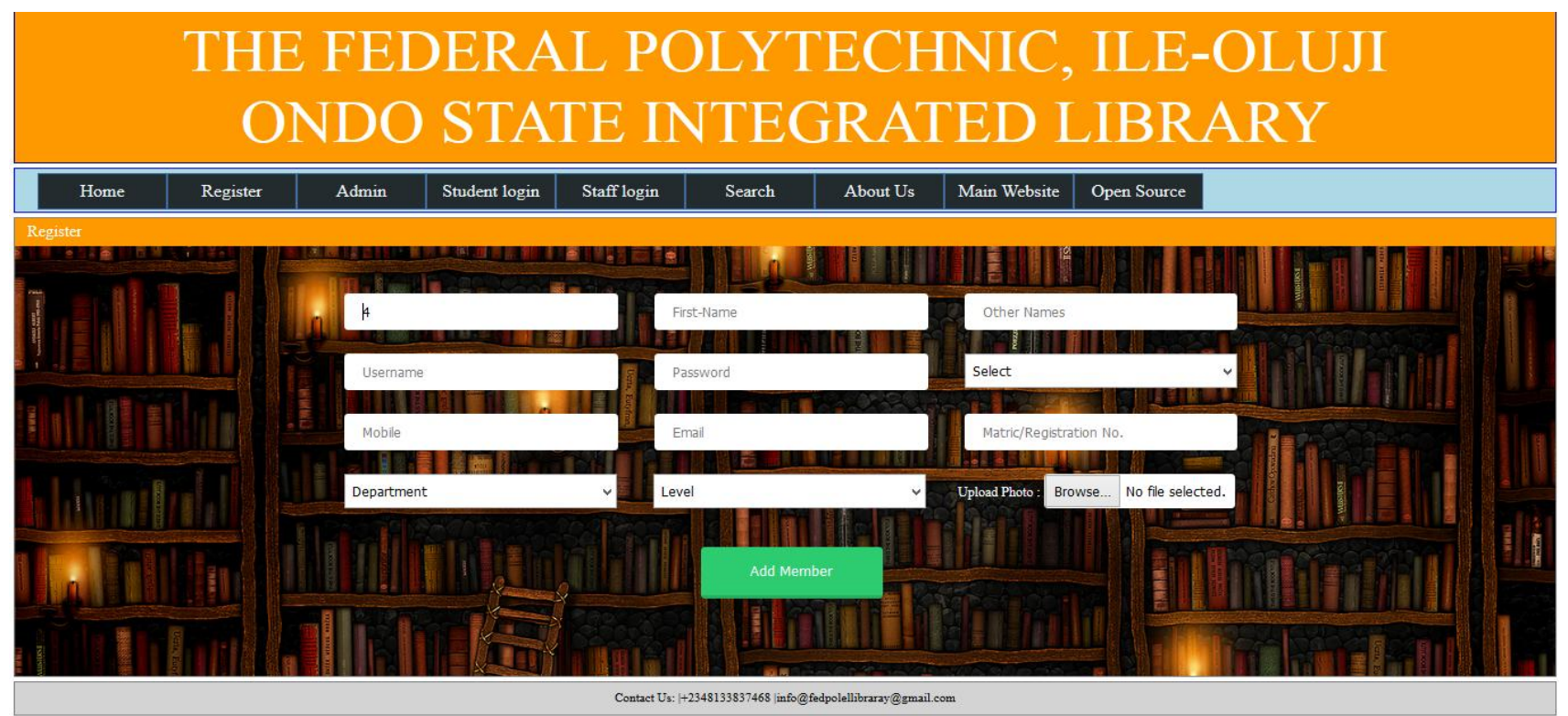

Figure 5: Registration Page

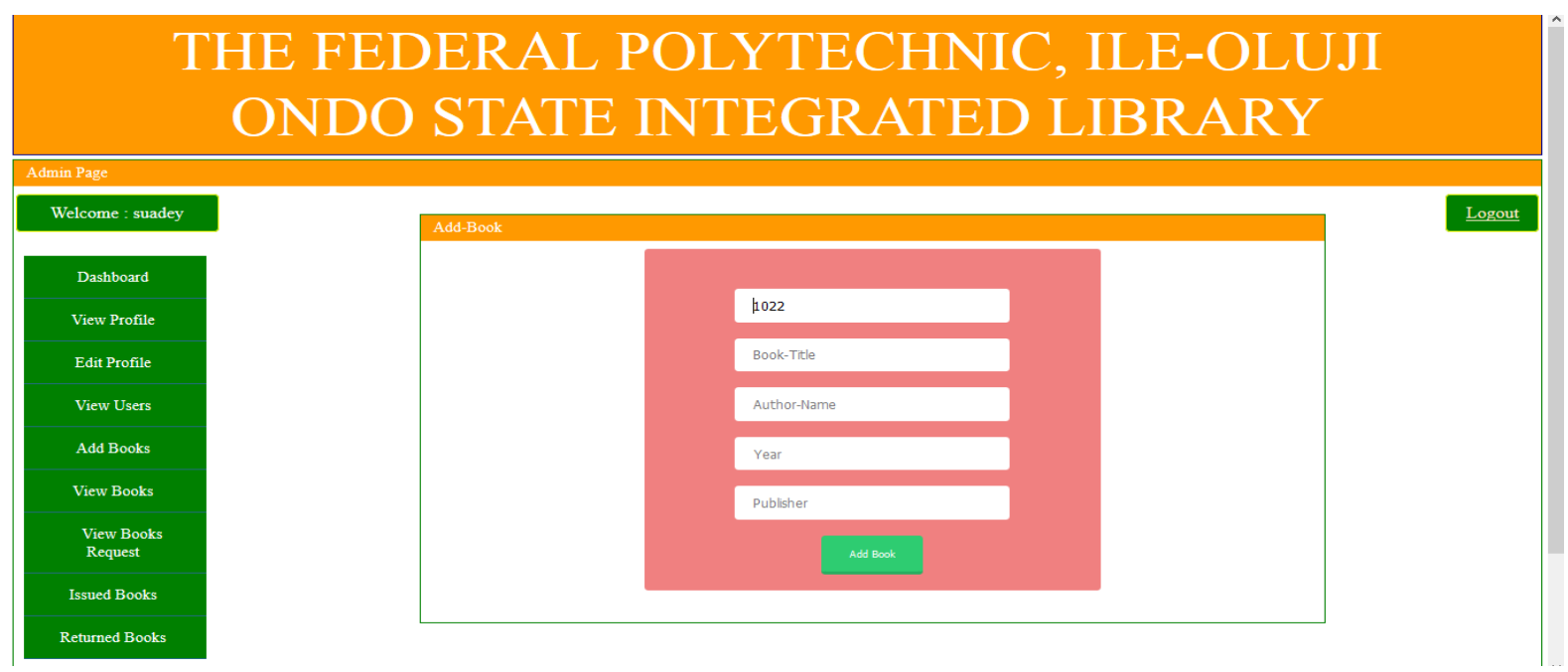

Figure 6: Add Book Page 


\subsection{Backend Results}

Details of database design for system are shown below.

Borrow Details Table: Borrow Details Table consists of the Book id, Issue id, Issue date, Return Book id, Return id, and return date.

User Table: The user table contains the user id, first name, last name, username, password, position, mobile, e-mail,

\subsection{Performance Test}

The designed system was tested on different platforms and certain amendments were made to ensure the system is performing the desired result. Each module was tested separately, and they were all performing desired output. The entire performance test carried out on the system shows that the system is performing desired result and it justifies the aim and objectives of the design. However, the admin is required matriculation number, department, level and passport. Pictorial representation of the User Table is presented in figure 7.

Book Table: Book Table consists of the Book Id, Title, Author, Year, Publishers, and Available.

to handle any error generated by the system as well as any security issues that may arise upon the implementation of the system.

All the books in the Federal Polytechnic Ile-Oluji were stored in the database of the system and the entire library was automated.

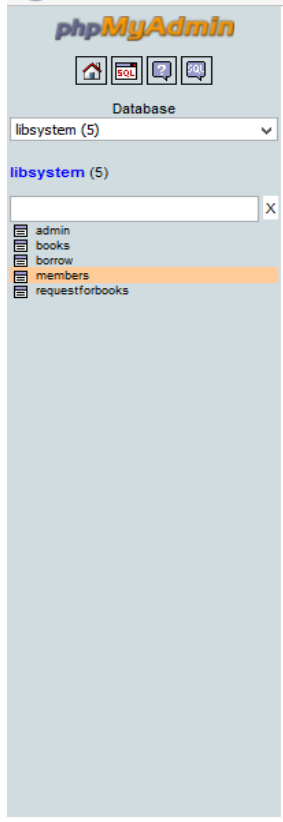

品 localhost 需 libsystem 、 国 members

Figure 7: User Table

\section{CONCLUSION}

The designed Robust Library Management System was developed to automate library activities, from registration of users, charging and discharging of books, online research among other packages in the design.

The following conclusions were therefore established from the design:

1. The system is working perfectly and meets the aim and objectives of the design

2. .From the analysis and assessment of the designed system, it can be safely concluded that the system is an efficient, cost effective, platform independent and security conscious Library Management System.

3. The new system is expected to attract more library users and provide user friendly environment for all users, especially those that are not conversant with library

4. The system will also ease the work of library staff as it will help them in carrying out their work more effectively and help them in automating library activities.

5. The system is flexible and can be easily modified to accommodate any modifications.

\section{REFERENCES}

[1] Neelakandan, B., Duraisekar, S., Balasubramani, R. \& Srinivasa, S. (2010). Implementation of automated library management system in the school of chemistry Bharathidasan University using Koha open source software. International Journal of Applied EngineeringResearch, Dindigul, 3 (1), 149-167.

[2] Baillon-Lalande, D. (1997). Multiple missions and necessary convictions. Bulletin des Bibliotheque de France, Vol.12 (1), pp. 35-40.

[3] Adamson, K., \& Veronica, E. (2008). JISC \& SCONULLibrary Management Systems Study.Sheffield, UK: Sero Consulting. p. 51.Retrieved from https://www.bag.web.id/IT/en/904-801/librarysystems_9922_bag.html

[4] Tochukwu, C., Nwachukwu-nwokeafor, K.C., \&Henrieta, U. (2015). Designing a web based digital library management system for institutions and colleges. International Journal of Innovative Science, Engineering \& Technology, Vol. 2 (3), 464-478. 
[5] Ademodi, D.T., \&Adepoju, E. O. (2009). Computer skill among Librarians in Academic Libraries on Ondo and Ekiti States, Nigeria. Library Philosophy \& Practice.

[6] Adomi, E. E., \&Anie, S. O. (2006). An assessment of computer literacy skills of professionals in Nigerian university libraries. Library Hi Tech News, Vol.23 (2), pp.10-14.

[7] Adebesin, T. (2015). Library Management System. FUOYE Repository, Department ofComputer Science,Faculty of Science, Federal University OyeEkiti, Ekiti State, Nigeria.

[8] Prabhakar, K., Rahul, K., Rajat, S., \&Vikram, P. S. (2014). Library management system. Unpublished B.Sc. Thesis. Department of Computer Science and Engineering, School of Engineering, Cochin University of Science \& Technology, Kochi, India.

[9] Remya, S.M., Susan, A.T., Jebril, M. M., Navaneeth, V., \& Justin, S. (2014). An android cloud based library management and authentication system. InternationalJournal of Advances in Electronics and Computer Science, 1 (2) 2393-2835.

[10] Moshood, A. A., \& Samuel, N. E. (2017). A web-based e-library system for tertiary institutions. InternationalJournal of Applied Information Systems (IJAIS), 12 (2), 17-22.
[11] Kumar, D. A., \& Mandal, S. (2013). Development of cloud computing in integrated library management and retrieval system. International Journal of Library andInformation Science, 5(10), 394-400.

[12] Mrinalini, G., Soniya, S., Bhagyashree, S., \&Akshata, P.(2016). Automated library management system. International Journal of Advanced Research inElectronics and Communication Engineering (IJARECE), 5 (1), 92-94.

[13] Vasupongayya, S., Keawneam, K., Sengloilaun, K., \&Emmawat, P. (2011). Open source library management system software: a review. International Journal of Computer, Electrical, Automation, Control and Information Engineering,5(5), 509-514.

[14] Royce, A., \& Winston, D. (1970). Managing the Development of Large Software Systems, Proceedings of IEEE WESCON 26 (August): pp. 329-330

[15] Bassil, Y. (2012). A simulation model for the waterfall software development life cycle. International Journalof Engineering and Technology (iJET), 2 (5), 2.

[16] King, A.E. (2010). Software Development Process Models in Practical Use. Harvard University Extension School.

[17] Sommerville, L. (1995). Software Engineering (5thed.). Lancaster University, Lancaster,England. 